\title{
O processo de des-re-territorialização dos moradores do conjunto residencial Geraldo Felippe no município de Paranavaí-PR: uma intervenção urbana a partir do programa Minha Casa Minha Vida
}

Dayane Alves de Souza Silva dayaneadmt2@hotmail.com Universidade Estadual de Maringá. Maringá. Paraná. Brasil.

Priscilla Borgonhoni Chagas priscillabchagas@gmail.com Maringá. Paraná. Brasil.

\begin{abstract}
RESUMO
Embora o espaço urbano seja produzido por diversos agentes sociais, o Estado exerce papel relevante em sua produção. Todavia, em determinadas situações ele recorre a fatores econômicos, sem considerar aspectos políticos, culturais e, principalmente, sociais. Com as políticas habitacionais, os indivíduos são deslocados para locais distantes do centro da cidade, passando por um processo de territorialização-desterritorializaçãoreterritorialização (T-D-R). Baseado nesta perspectiva, este artigo tem por objetivo compreender como ocorreu o processo de (re)territorialização dos moradores do Conjunto Residencial Geraldo Felippe no município de Paranavaí - PR, a partir da intervenção do Programa Minha Casa Minha Vida (faixa 1). Assim, foi conduzido um estudo qualitativo e descritivo, envolvendo entrevistas semiestruturadas com os moradores. Para a interpretação dos dados coletados, utilizou-se a técnica da análise de conteúdo. Constatouse que os moradores, de modo explícito, tem um sentimento de felicidade pela "casa própria", entretanto, implicitamente, existem diferenças em relação ao território que viviam antes e o que vivem agora. Os principais resultados sugerem que na formulação de uma política habitacional deve-se ter uma visão integradora, não negligenciando os aspectos territoriais, uma vez que tais intervenções impactam a organização territorial da cidade e, consequentemente, o cotidiano dos indivíduos.
\end{abstract}

PALAVRAS-CHAVE: Espaço urbano. Território. Processo de territorializaçãodesterritorialização-reterritorialização. Programa Minha Casa Minha Vida. Conjunto Residencial Geraldo Felippe. 


\section{INTRODUÇÃO}

Nas últimas décadas os estudos da área de Administração têm deixado de seguir tendências disseminadas pelos países centrais e focado mais na realidade brasileira, buscando questionar a racionalidade das teorias tradicionais e mostrar que as coisas não são necessariamente aquilo que aparentam ser (Davel; Alcadipani, 2002). No Brasil, este fenômeno emerge desde o final da década de 1960, com autores como Alberto Guerreiro Ramos, Maurício Tragtenberg, Fernando Carlos Prestes Motta, Fernando Guilherme Tenório e José Henrique de Faria (Davel; Alcadipani, 2002).

Congruente $a$ isso, o espaço para a crítica da realidade na análise organizacional brasileira ainda é muito limitado, tendo em vista que preponderam artigos baseados em perspectivas funcionalistas e positivistas, em detrimento de referenciais teóricos críticos (Davel; Alcadipani, 2002; Misoczky; Amantino-deAndrade, 2005)

Nesse contexto, tratar conceitos relativos à produção do espaço e território se faz importante. Embora ainda sejam incipientes no campo da Administração, eles vêm ganhando certa notoriedade no campo dos Estudos Organizacionais, permitindo analisar as relações sociais e espaciais, principalmente quando relacionadas à influência das estruturas capitalistas.

Assim, em virtude de o espaço urbano da cidade ser dotado de relações sociais que apresentam características como fragmentadas e articuladas, fica evidente que no contexto atual da sociedade capitalista, poucos têm muito e muitos têm pouco, gerando, desta forma, uma segregação socioespacial. Porém, isso se deve às estratégias dos agentes produtores do espaço urbano que, como bem explica Corrêa (2000), agem conforme seus próprios interesses.

Com base nestes pressupostos, no segundo mandato de Luís Inácio Lula da Silva, como presidente da república, que se estendeu de 2007 a 2010, foi apresentado o Programa Minha Casa Minha Vida (PMCMV) visando diminuir o déficit habitacional e aquecer o setor da construção civil que se afetara com a crise internacional do ano de 2008.

O PMCMV se apresenta dividido em quatro faixas: 1, 1,5, 2 e 3 . No caso da faixa 1 vê-se que as moradias estão localizadas em áreas periféricas da cidade, forçando os indivíduos, que muitas vezes não têm outra alternativa de moradia, a morarem em lugares segregados socioespacialmente. Então, os sujeitos que viviam em um dado lugar, veem-se obrigados a se (re)territorializarem em seu novo local, visto que agora possuem a "casa própria". Desta forma, pode-se dizer que ocorre o processo de territorialização-desterritorialização-reterritorialização (T-D-R), entendido como um processo de enraizamento, rompimento e criação de novas formas de ocupação do espaço vivido. E foi a partir deste olhar que procurou-se compreender o fenômeno em questão.

Com base neste contexto, o município de Paranavaí está localizado na região noroeste do Paraná contando com 87.316 habitantes, segundo dados do IBGE (2016). Paranavaí possui vários empreendimentos habitacionais financiados pelo PMCMV, PAC e COHAPAR. Neste estudo, o foco está nos empreendimentos viabilizados pelo Programa Minha Casa Minha Vida (faixa 1), especificamente o Conjunto Residencial Geraldo Felippe. O interesse se deu por estar localizado 
numa área periférica da cidade, além das pesquisadoras compreenderem como os sujeitos que nele residem foram se (re)territorializando.

Desse modo, o objetivo deste estudo consiste em compreender como ocorreu o processo de (re)territorialização dos moradores do Conjunto Residencial Geraldo Felippe no município de Paranavaí - PR, a partir da intervenção do Programa Minha Casa Minha Vida (faixa 1).

O trabalho está estruturado em oito seções, além desta parte introdutória. Em seguida são abordados assuntos pertinentes à produção do espaço urbano, território e o Programa Minha Casa Minha Vida. Posteriormente são apresentados os procedimentos metodológicos, seguidos da apresentação e análise dos dados. Na próxima seção são discutidas as conclusões. E por fim, o arcabouço teórico utilizado para elaboração deste trabalho é apresentado.

\section{PRODUÇÃO DO ESPAÇO URBANO E AGENTES SOCIAIS}

O espaço urbano trata-se de onde os indivíduos estabelecem relações sociais, sendo dotado de muitas contradições e que são perceptíveis conflitos de interesses entre o capital e o social. Conquanto, o espaço urbano representa toda organização social, política, econômica e o modo de vida característico das cidades, não restringindo o seu entendimento somente ao espaço físico (Coelho, 2012). Nesse sentido, sob a lógica do espaço urbano, surge a questão: o que é cidade? No campo dos Estudos Organizacionais, autores como Saraiva e Carrieri (2012) ao trabalharem com o conceito de organização-cidade, compreendem a cidade enquanto organização, o que permite um olhar organizacional da dinâmica urbana, oferecendo uma ampla gama de oportunidades para a observação da vida social organizada.

Concernente a isso, Fischer $(1997$, p. 75$)$ ao considerar a cidade como uma megaorganização, alega que ambas possuem "os mesmos traços distintos de complexidade, diversidade, singularidade, pluralidade e contradição", sendo que no mesmo espaço urbano expandem-se das mais simples às mais complexas, mas todas possuindo o mesmo marco identitário.

Com base nesta linha de pensamento, Corrêa (2013) considera a cidade como um espaço urbano e o interesse em estudá-la reside no fato de que ela é o lugar onde vive parcela crescente da população, onde os investimentos de capital são maiores e, principalmente, o lugar dos conflitos sociais.

Baseado nestas reflexões, na concepção de Corrêa (2004, p. 9) "eis o que é espaço urbano: fragmentado e articulado, reflexo e condicionante social, um conjunto de símbolos e campo de lutas". Sendo assim, ele é um produto social, resultado de ações acumuladas por meio do tempo, sendo criadas por agentes que produzem e consomem o espaço.

Diante do explicitado, para Côrrea (2004, p. 7) este espaço urbano fragmentado trata-se do:

conjunto de diferentes usos da terra justapostos entre si. Tais usos definem áreas, como o centro da cidade, local de concentração de atividades comerciais, de serviços e de gestão, áreas industriais, 
Além disso, Corrêa $(2004$, p. 8) reforça que "o espaço da cidade capitalista é fortemente dividido em áreas residenciais segregadas, refletindo a complexa estrutura social em classes". E corroborando esta ideia, chama a atenção o argumento de Lefebvre (2000), pois ele diz que esse espaço homogêneo se fragmenta em pedaços, produzindo cortiços, favelas, guetos isolados e conjuntos mal ligados aos arredores e aos centros da cidade. Isso faz com que seja gerada uma hierarquização, resultando em espaços devidamente demarcados, como espaços residenciais, espaços comerciais, espaços de lazer, espaços dos ricos, espaços dos pobres, etc.

Por conta disso, Lefebvre (2000) afirma que o capitalismo transformou a terra em mercadoria, adquirindo um valor de troca. Isso significa que os modos possíveis de apropriação devem realizar-se nos limites e interstícios da propriedade privada do solo urbano, delimitando o acesso dos cidadãos à moradia ao mesmo tempo em que determina e orienta outras formas de uso, o que faz com que seja gerada tal desigualdade (Carlos, 2007). Aqui cabe enfatizar que os mais pobres, muitas vezes, não possuem acesso a essas 'positividades', visto que "são 'depositados' nas periferias distantes do consumo, do trabalho e do lazer, ou separados dos ricos por muros e outros tipos de barreiras cada vez mais visíveis na paisagem urbana" (BOTELHO, 2007, p. 14).

Contudo, na visão de Corrêa (2013) a produção do espaço não é resultado da 'mão invisível do mercado', mas sim consequência da ação de agentes sociais concretos, dotados de interesses, estratégias e práticas espaciais próprias, em que cada um agirá sobre o espaço urbano modelando-o conforme seus interesses e estratégias. Desta forma, torna-se imprescindível o conhecimento sobre quem produz esse espaço e como ele está sendo apropriado e usado. Como caracteriza Corrêa (2004) os agentes sociais que fazem e refazem a cidade são os proprietários dos meios de produção, os proprietários fundiários, os promotores imobiliários, o Estado e os grupos sociais excluídos.

Cabe salientar, todavia, que dentre todos os agentes sociais o Estado é o que usufrui de instrumentos mais amplos para atuar na produção do espaço, pois ele possui instrumentos de caráter regulatório, podendo definir o que pode ser feito na cidade por meio de legislações específicas (COELHO, 2012). Mas, é preciso destacar que a atuação deles não se faz isoladamente. Pelo contrário, eles atuam em conjunto no processo de produção concreta de um bairro residencial ou de um distrito industrial, embora realizando estratégias que atendam aos seus próprios interesses (Corrêa, 2004). Isso porque, segundo Almeida e Melchiors (2017), o Estado não é uma estrutura independente do sistema de que faz parte, mas tratase de um agente que sofre as influências do meio em que está inserido, refletindo as contradições existentes na sociedade capitalista. Deste modo, Botelho (2007, p. 28) reforça que "o espaço produzido e consumido no modo de produção capitalista está repleto de contradições".

Nesse sentido, a luta pelo espaço, a intervenção reguladora do Estado e as demais ações dos agentes sociais provocam a existência de diversos fenômenos, tais como a informalidade, a periferização, a segregação e a desterritorialização (Moura, 2014). Para tanto, no próximo tópico são abordados os conceitos de território, iluminando consequentemente o processo T-D-R, que dizem respeito às relações de poder sobre o espaço urbano. 


\section{ABORDAGENS SOBRE TERRITÓRIO E O PROCESSO DE TERRITORIALIZAÇÃO- DESTERRITORIALIZAÇÃO-RETERRITORIALIZAÇÃO (T-D-R)}

O termo território é utilizado por várias ciências, apresentando diversos significados em diferentes contextos. É por isso que Haesbaert (2004) vai chamálo de um conceito polissêmico, pois por mais que seja central a Geografia, ele é utilizado em outras áreas como Antropologia, Sociologia, Psicologia, Economia, além dos Estudos Organizacionais.

Ao abordar o conceito de território, Souza (2009) diz que em certos momentos ele apresentou as características de um modismo, muitas vezes, sendo 'coisificado' com se fosse um pedaço tangível da superfície terrestre. Nesse sentido, há uma relação entre os conceitos de espaço e território? Embora os conceitos de espaço e território não sejam sinônimos, ambos são indissociáveis, todavia, o espaço é anterior ao território, em que este se forma a partir do espaço, por meio de uma ação conduzida por um ator em qualquer escala. Assim, "ao se apropriar de um espaço concreta ou abstratamente [...] o ator territorializa o espaço" (Raffestin, 1993, p. 143) por meio das relações sociais (Candiotto; Santos, 2009). Ademais, Raffestin (1993) reafirma que o território se apoia no espaço, mas não é o espaço, visto que é uma produção a partir dele.

Com base nestas concepções, torna-se pertinente conceituar território. Para Haesbaert (2005) o termo possui uma conotação mais material e outra mais simbólica, pois etimologicamente, territorium tem a ver com a dominação (jurídico-política) da terra e com a inspiração do terror desta dominação, além de o território poder inspirar a identificação e a efetiva apropriação.

Durante certo tempo o conceito de território foi concebido como uma determinada porção da terra apropriada por um grupo humano, sendo na maioria das vezes dominada pelo Estado (Candiotto; Santos, 2009). No entanto, segundo Lefebvre (2000), os espaços não são neutros, mas são marcados por ideologias e estratégias da classe dominante, passando a ser agente produtor das relações sociais.

Em sua obra "Por uma geografia do poder", publicada originalmente em 1980, Claude Raffestin (1993) faz uma reflexão crítica sobre as relações de poder centradas no Estado, baseando-se nas ideias de Michel Foucault. Deste modo, Raffestin amplia o conceito de território não o limitando ao poder do Estado (Candiotto; Santos, 2009). Assim, "do Estado ao indivíduo passando por todas as organizações pequenas e grandes, encontram-se atores sintagmáticos que 'produzem' o território" (Raffestin, 1993, p. 152). Na abordagem deste autor, o poder se baseia nas relações sociais estando presente nas ações do Estado, das instituições, das empresas e, de modo sintetizado, nas relações sociais que são efetivadas na vida cotidiana. O Poder visível, identificável e controlado é aquele pertencente ao Estado, já o poder presente em cada relação social, está implícito em todos os lugares, mas por detrás do Poder do Estado (Candiotto; Santos, 2009).

No plano da geografia brasileira, a utilização dos conceitos de território, territorialidade e territorialização intensificou-se a partir da década de $1990 \mathrm{com}$ o surgimento de novas leituras, tais como as relações sociais cotidianas, o poder e as diversas dimensões que o compõem (Candiotto; Santos, 2009), onde destacamse autores como Milton Santos, Rogério Haesbaert, Marcelo Lopes de Souza e Marcos Aurélio Saquet. 
Ao se trabalhar com uma visão integradora, o território "não pode ser considerado nem estritamente natural, nem unicamente político, econômico ou cultural" (Haesbaert, 2004, p. 112). Ou seja, o território não deve ser visto nem simplesmente como um objeto em sua materialidade, nem como um mero conceito elaborado pelo pesquisador. Mas, deve abarcar todos os aspectos: cultural, natural, político, econômico, simbólico (Haesbaert, 2004).

Baseado neste cenário, os territórios não devem ser vinculados somente ao Estado, visto que podem surgir por meio de escalas temporais, podendo formarse e dissolver-se de modo longo e rápido, seja em séculos, décadas, anos, meses, semanas, dias ou até mesmo horas, bem como ser estáveis e instáveis, ter existência regular, mas periódica (Souza, 2012).

Assim sendo, o território é um "espaço definido e delimitado por e a partir de relações de poder" (Souza, 2012, p. 78), sendo que a questão primordial é quem domina ou influencia e como domina ou influencia esse espaço.

Assim como o poder não se circunscreve ao Estado nem se confunde com a violência e a dominação [...] da mesma forma o conceito de território deve abarcar infinitamente mais que o território do Estado-Nação. Todo espaço definido e delimitado por e a partir de relações de poder é um território, do quarteirão aterrorizado por uma gangue de jovens até o bloco constituído pelos países-membros da OTAN (Souza, 2012, p. 111).

Desse modo, os territórios são construídos e descontruídos em diferentes escalas espaciais e temporais, não sendo limitado somente ao Estado-Nação (Souza, 2012). E é por isso que esta conceituação servirá de alicerce para esta pesquisa. Isso porque, segundo Souza (2012) em qualquer contexto o território tem a ver com poder, não se restringindo apenas ao tradicional 'poder político'. Ou seja, ele diz respeito tanto ao poder no sentido mais concreto, de dominação, quanto ao poder no sentido mais simbólico, de apropriação. Assim, todo território é em diferentes combinações, funcional e simbólico, pois as pessoas exercem domínio sobre o espaço tanto para realizar funções quanto para produzir significados (Haesbaert, 2005).

Visto que o território abrange a porção da superfície terrestre apropriada por um grupo social, entra em cena o conceito de territorialidade, sendo definida por Sack (1986, p. 3) "como uma estratégia espacial para afetar, influenciar ou controlar fontes e pessoas, controlando a área; e, como uma estratégia, a Territorialidade pode ser ligada e desligada". Em síntese, ela é uma forma de comportamento espacial, dizendo respeito em como as pessoas usam a terra, como se organizam no espaço e como dão significado ao lugar (Sack, 1986).

Outra contribuição de Sack trata-se da combinação de diferentes níveis escalares, onde tanto a territorialidade como o território são efetuados nos níveis do indivíduo, da casa, do bairro, do estado, do país e do mundo (Saquet, 2009), significando a apropriação social do ambiente.

No intuito de complementar a discussão, Saquet (2009) alega, ainda, que o indivíduo vive diferentes temporalidades e territorialidades em um processo constante e concomitante de desterritorialização e reterritorialização que gera sempre novas territorialidades e novos territórios que contêm traços/características dos velhos territórios e territorialidades. 
Partindo deste pressuposto, pode-se trazer à tona o conceito do processo TD-R, que como mencionado por Haesbaert (2007) consiste na criação e desaparecimento dos territórios. Nesse contexto, a territorialização é compreendida como o "conjunto de múltiplas formas de construção/apropriação (concreta e/ou simbólica) do espaço social, em sua interação com elementos como o poder (político/disciplinar), os interesses econômicos, as necessidades ecológicas e o desejo/a subjetividade" (Haesbaert, 2006, p. 45). E associado a este conceito tem-se o processo de desterritorialização e reterritorialização, compreendidos respectivamente como a destruição e (re)construção dos territórios. Assim, o homem vive num processo T-D-R, uma vez que está "sempre passando de um território para outro, abandonando territórios, fundando novos" (Haesbaert; Bruce, 2002, p. 12).

Embora muitos acreditem que estes termos ocorram de maneira isolada, "a desterritorialização está indissociavelmente ligada com a (re)territorialização" (Haesbaert, 2000, p. 198), visto que o indivíduo sempre está criando, destruindo e (re)criando territórios constantemente, mas nunca abandonando o território anterior. Na desterritorialização, há a perda do território inicialmente apropriado e construído, a supressão dos limites, das fronteiras, como afirma Saquet (2013) e na reterritorialização, uma re-produção de elementos do território anterior.

Assim, o processo de desterritorialização "pode ser tanto simbólico, com a destruição de símbolos, marcos históricos, identidades, quanto concreto, materialpolítico e/ou econômico, pela destruição de antigos laços/fronteiras econômicopolíticas de integração" (Haesbaert, 2000, p. 181), pois o cotidiano se compõe de materialidades e imaterialidades.

Desta forma, os elementos principais da territorialização também estão presentes na desterritorialização, tais como: há perda, mas há reconstrução da identidade, mudanças nas relações de poder, de vizinhança, de amigos, de novas relações sociais, de elementos culturais, em que são reterritorializados. Assim, os processos de territorialização, desterritorialização, reterritorialização (T-D-R) estão ligados, completam-se incessantemente e também estão em unidade (Saquet, 2007), como se vê nas políticas habitacionais.

\section{O PROGRAMA MINHA CASA MINHA VIDA (PMCMV)}

O Programa Minha Casa Minha Vida (PMCMV), instituído pela Lei no. 11.977 de 07 de Julho de 2009, trata-se de um programa do governo federal anunciado com o objetivo de promover a construção de milhares de moradias no Brasil, permitindo o acesso a casa própria às famílias de baixa renda e, consequentemente, diminuindo o déficit habitacional. Entretanto, muitos autores ressaltam que a criação do PMCMV deveu-se aos temores quanto aos efeitos no Brasil com a crise financeira mundial de 2008, no qual o governo federal lançou este programa para aquecer ainda mais o setor da construção civil (Ferreira, 2012; Klintowitz; Rufino, 2014; Mineiro; Rodrigues, 2012).

O Programa Minha Casa Minha Vida recebe aporte de recursos públicos, representando atualmente a principal estratégia governamental de provisão habitacional, objetivando possibilitar a redução do déficit brasileiro, além de impulsionar o crescimento econômico do país, conforme apontam Melchiors (2015) e Melchiors e Almeida (2015). 
A 1a fase do programa compreendeu o período de março de 2009 a meados de 2011. Esta fase foi instituída pela Medida Provisória no. 459 de 25 de março de 2009, posteriormente convertida na Lei no. 11.977 de 7 de julho de 2009 e demais normas infra legais, em que estabeleceu-se como meta a construção de um milhão de novas moradias. Em sua 2a fase, iniciada em meados de 2011 e finalizada em 2014, dobrou-se a meta da primeira fase, prevendo-se a construção de mais dois milhões de unidades habitacionais (Lago, 2012; Rolnik et al., 2015). Hoje, o Programa está em sua 3 a fase, em que prevê a entrega de mais de 2 milhões de moradias até 2018 , com recursos que chegam ao total de $\mathrm{R} \$ 210,6$ bilhões.

Com base nesse cenário, o PMCMV atende quatro faixas de renda distintas, possuindo metas, mecanismos de contratação e subvenções econômicas diferentes (Rolnik et al., 2015).

Quadro 1. Faixas de renda atendidas pelo PMCMV.

\begin{tabular}{|c|c|c|}
\hline $\begin{array}{c}\text { Renda Familiar } \\
\text { Mensal }\end{array}$ & $\begin{array}{c}\text { Faixa do } \\
\text { MCMV }\end{array}$ & Característica \\
\hline Até $R \$ 1.800,00$ & FAIXA 1 & $\begin{array}{c}\text { Até } 90 \% \text { de subsídio do valor do imóvel. Pago em até 120 } \\
\text { prestações mensais de, no máximo, R\$ 270,00, sem juros }\end{array}$ \\
\hline Até $R \$ 2.350,00$ & FAIXA 1,5 & Até $R \$ 45.000,00$ de subsídio, com 5\% de juros ao ano \\
\hline Até $R \$ 3.600,00$ & FAIXA 2 & Até $R \$ 27.500,00$ de subsídio, com 6\% a 7\% de juros ao ano \\
\hline Até $R \$ 6.500,00$ & FAIXA 3 & $8,16 \%$ de juros ao ano \\
\hline \multicolumn{3}{|c|}{ Fonte: Ministério das Cidades, 2016. (Dados organizados pelos autores). } \\
\hline
\end{tabular}

Lembrando que nas fases 1 e 2 do programa não existia a faixa 1,5. Ela foi inclusa no MCMV 3. Além disso, em sua segunda fase (MCMV 2), o programa passou a integrar o Programa de Aceleração do Crescimento (PAC) em sua vertente de investimentos em infraestrutura social e urbana, que inclui ações de urbanização de favelas (Balbim; Krause; Neto, 2015). Na Faixa 1 os indivíduos se inscrevem no cadastro das Prefeituras e aguardam as possibilidades que serão oferecidas e nas Faixas 2 e 3 eles adquirem os imóveis junto às construtoras ou em feirões da CAIXA (ALMEIDA; MELCHIORS, 2017).

No processo de operacionalização do PMCMV há a interação entre cinco grandes agentes: (1) Ministério das Cidades, representante do poder público na escala federal; (2) governos estaduais e/ou municipais bem como outros órgãos representantes do poder público na escala local; (3) Caixa Econômica Federal (CAIXA), instituição financeira que funciona como companhia pública do Governo Federal, assim como as demais instituições financeiras introduzidas no programa a partir de 2011; (4) construtoras e incorporadoras, representantes do setor privado; e (5) beneficiários (Nascimento et al., 2015).

Contudo, Cardoso, Mello e Jaenisch (2015) alegam que o setor privado passa a ser o principal agente promotor desta política, cabendo às empresas construtoras e incorporadoras a iniciativa de produzir, assim como o direito de tomar decisões referentes à escolha dos terrenos, tipologia do empreendimento, tecnologias construtivas, número de unidades, qualidade dos materiais, até mesmo a faixa de renda à qual o empreendimento seria destinado. Melchiors e Almeida (2017) destacam que no PMCMV as construtoras e incorporadoras exercem papel de destaque como promotoras e definidoras dos empreendimentos. E assim, o poder público assume papel secundário. 
Por esta razão, determinados aspectos do programa têm sido alvos de críticas, principalmente com relação ao déficit habitacional, à segregação social no espaço e à localização geográfica dos empreendimentos, uma vez que o programa acaba por gerar uma nova onda de periferização nas cidades brasileiras (Marques; Rodrigues, 2013).

Consoante a estes argumentos, são recorrentes as críticas feitas ao Programa, visto que há a construção de conjuntos habitacionais afastados do centro das cidades, não havendo o oferecimento de infraestrutura adequada aos moradores. Canodá, Tirelli e Areosa (2017) argumentam, por exemplo, que mesmo que os programas habitacionais tenham sido formulados baseados numa perspectiva de ampliação do direito à cidade, as remoções ou deslocamentos de indivíduos e famílias resultaram em diversas transformações nos modos de vida desses grupos. Os autores ainda reforçam que essas dinâmicas urbanas interferiram nas relações dos indivíduos e das famílias com a própria cidade, as quais ocasionaram alterações nas suas relações com os serviços oferecidos, com os espaços de trabalho, com as instituições públicas, com suas relações de amizade e de vizinhança, dentre outros.

Nas palavras de Silva e Tourinho (2015) na busca pelas 'melhores' localizações, os conjuntos habitacionais destinados aos segmentos de menor renda são construídos em locais afastados da malha urbana e, consequentemente, distantes dos setores de comércio e serviços. Neste sentido, alguns dos problemas encontrados nessas localizações dizem respeito à "infraestrutura viária precária, insuficiência de transporte coletivo, distância significativa dos postos de trabalho e expansão desordenada do tecido urbano" (Silva; Tourinho, 2015, p. 404). De acordo com os mesmos autores, em virtude da inserção dos conjuntos habitacionais na malha urbana ser determinada pelo poder de compra dos mutuários, de modo que 'mora melhor' aquele que pode pagar mais pela habitação, fica nítido o processo de segregação que tem marcado a produção do espaço urbano pelas políticas habitacionais.

Tal fato fortalece o processo de desterritorialização, que pode ser entendido como uma perda de vínculos com determinado espaço, provocado principalmente por um afastamento geográfico que gera danos econômicos e sociais, uma vez que emerge uma profunda dificuldade de acesso aos recursos mais básicos de vivência no cotidiano (Moura, 2014). Nesse sentido, Cadoná, Tirelli e Areosa (2017) afirmam que ao mesmo tempo em que garante o acesso à moradia, o deslocamento dos indivíduos por meio da implementação de programas habitacionais repercute em diferentes dimensões de reprodução social das famílias contempladas e, muitas vezes, não produz uma maior inclusão social, resultando, por exemplo, num longo deslocamento entre casa e trabalho (CARVALHO; PATRÍCIO; SCHUETT, 2014).

Assim, a partir do exposto fica evidente que o PMCMV gera certa contradição, uma vez que embora seu objetivo seja diminuir o déficit habitacional, ele busca aquecer o mercado imobiliário e de construção diante do contexto de crise, causando um processo de desterritorialização com os sujeitos contemplados, principalmente no que tange a faixa 1. 


\section{PROCEDIMENTOS METODOLÓGICOS}

Para este estudo foi utilizada uma pesquisa do tipo descritiva, pois seu foco "reside no desejo de conhecer a comunidade, seus traços característicos, suas gentes, seus problemas [...] seus valores [...]" (Triviños, 1987, p. 110). Sendo assim, este tipo de pesquisa condiz com o objetivo do trabalho, visto que busca conhecer como os moradores do Conjunto Residencial Geraldo Felippe vêm se (re)territorializando neste novo espaço de que agora fazem parte. Quanto à natureza, trata-se de uma pesquisa qualitativa que, segundo Vieira e Zouain (2005) atribui importância fundamental aos depoimentos dos atores sociais envolvidos, aos discursos e aos significados transmitidos por eles. O locus da pesquisa trata-se do Conjunto Residencial Geraldo Felippe, localizado no município de Paranavaí PR, que foi entregue no ano de 2015. O interesse se deu por estar localizado numa área periférica da cidade, além de entender como os moradores tem se relacionado/identificado com o novo espaço de vivência.

Como instrumento de coleta de dados, foi utilizada a entrevista semiestruturada. Desta forma, foram realizadas oito entrevistas com moradores do Conjunto Residencial Geraldo Felippe, utilizando-se da técnica da "bola de neve", além do conceito de "ponto de saturação", em que as entrevistas foram interrompidas quando as falas começaram a se tornar repetitivas e não traziam novas contribuições ao estudo.

As entrevistas aplicadas aos moradores ocorreram no decorrer do mês de dezembro de 2016, além de serem gravadas mediante autorização dos participantes. A partir daí, elas foram transcritas na íntegra. Porém, no intuito de manter em sigilo as identidades dos entrevistados, nesta pesquisa são utilizados nomes fictícios.

A pesquisa também se apropriou de dados secundários, e entre as principais fontes consultadas pode-se citar o Instituto Brasileiro de Geografia e Estatística IBGE, o Programa Minha Casa Minha Vida - PMCMV, além do acesso ao site da Prefeitura de Paranavaí e observações e análises no Google Mapas. Segundo Minayo (1994) os dados secundários são aqueles que já se encontram disponíveis, porém possuem uma relação direta com o acontecimento registrado.

Para a interpretação dos dados obtidos foi utilizada a técnica da análise de conteúdo, valendo-se da organização de toda a documentação e transcrição das entrevistas na íntegra, possibilitando, assim, a compreensão das falas dos sujeitos. Bardin (1977) propõe que as fases da análise de conteúdo organizam-se em torno dos seguintes itens: pré-análise, exploração do material, tratamento dos resultados, inferência e interpretação. Ressalta-se que todos os dados obtidos foram analisados a partir das seguintes categorias: espaço vivido antes da mudança ao Conjunto Residencial Geraldo Felippe, modificação das práticas cotidianas, adaptação ao novo contexto, apropriação do espaço urbano pelos diversos agentes e a segregação socioespacial decorrente da ação destes agentes. Além disso, foi utilizado o recurso negrito para dar destaque em algumas falas dos entrevistados. 


\section{MUNICÍPIO DE PARANAVAÍ E A IMPLANTAÇÃO DO PROGRAMA MINHA CASA MINHA VIDA}

O município de Paranavaí está localizado na região noroeste do estado do Paraná, conforme pode ser observado na figura abaixo.

Figura 1. Localização do município de Paranavaí-PR

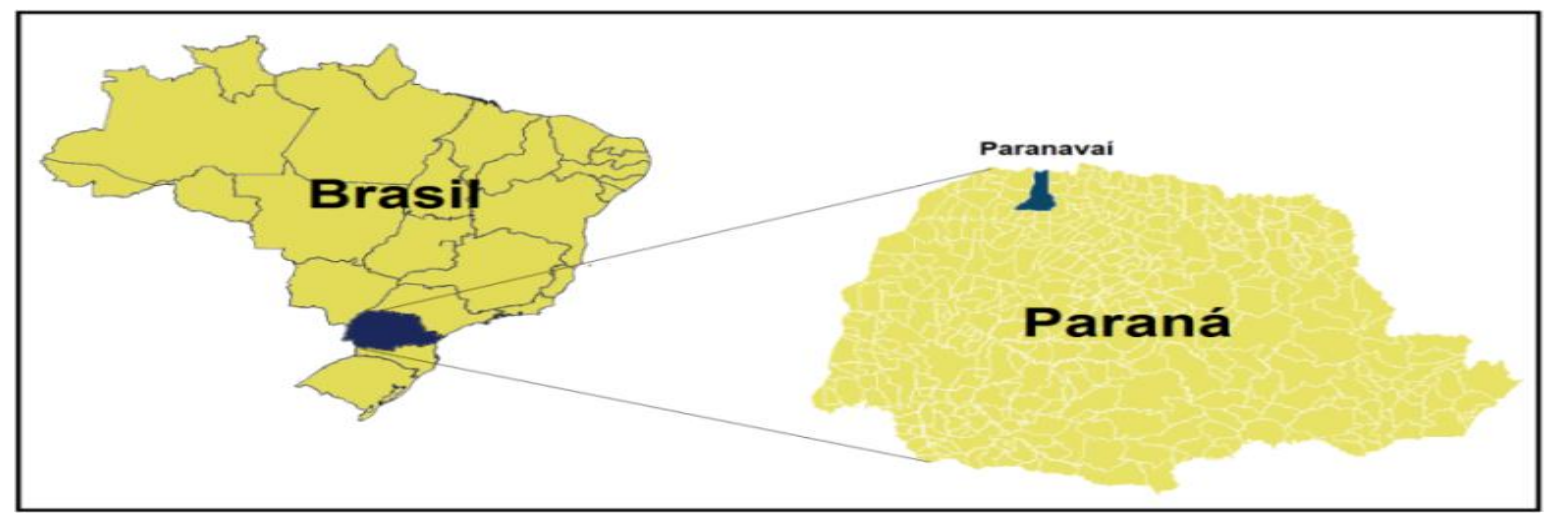

Fonte: IBGE, 2016. (Dados organizados pelos autores).

Nesse sentido, o município de Paranavaí, cuja denominação é originada da junção dos nomes do rio Paraná e do rio Ivaí, foi criado pela Lei no. 790 de 14 de Dezembro de 1951 com o desmembramento do município de Mandaguari. Na década de 1950, a população de Paranavaí era constituída de 25.520 habitantes, aumentando para 63.189 em 1960 (Silva, 2014).

Atualmente, Paranavaí possui um total de 87.316 habitantes, unidade territorial de $1202.266 \mathrm{~km}^{2}$ e densidade demográfica de $67.86 \mathrm{hab} / \mathrm{km}^{2}$, segundo dados do IBGE (2016). Neste cenário, o município constitui-se de seis distritos administrativos, sendo eles: Cristo Rei, Graciosa, Mandiocaba, Quatro Marcos, Piracema e Sumaré e contempla um total de 239 (duzentos e trinta e nove) bairros, o que equivale a jardins, vilas, condomínios, chácaras, conjuntos habitacionais, residenciais, casas populares e moradias.

Ademais, Paranavaí possui 5 (cinco) empreendimentos viabilizados por meio do Programa Minha Casa Minha Vida (faixa 1), desde a sua instituição no ano de 2009 (Quadro 2). Entretanto, o foco deste estudo está no Conjunto Residencial Geraldo Felippe.

Quadro 2. Empreendimentos do Programa Minha Casa Minha Vida (faixa 1) no município de Paranavaí (2009/2016).

\begin{tabular}{|c|c|c|}
\hline Nome do empreendimento & $\begin{array}{c}\text { Número de unidades } \\
\text { habitacionais }\end{array}$ & Data de entrega \\
\hline Conjunto Residencial Flávio Ettore Giovine & 316 unidades & Novembro/2011 \\
\hline Conjunto Residencial Vila Operária II & 180 unidades & Junho/2014 \\
\hline Conjunto Residencial Geraldo Felippe & 445 unidades & Junho/2015 \\
\hline Conjunto Residencial Francisco Luis de Assis & 269 unidades & Junho/2015 \\
\hline Conjunto Residencial Luiz Lorenzetti & 580 unidades & Março/2016 \\
\hline
\end{tabular}

Fonte: Diretoria de Habitação da Prefeitura Municipal de Paranavaí (2016).

O Conjunto Residencial Geraldo Felippe foi construído no Jardim São Jorge, 
Brasil, em que o valor do investimento para esta obra foi de $\mathrm{R} \$ 26.700 .000,00$. Como também, as casas foram executadas no padrão de dois quartos, sala, cozinha, banheiro e área de serviço, com cerca de $40 \mathrm{~m}^{2}$, sendo todas adaptáveis para portadores de deficiência física (Prefeitura de Paranavaí, 2016).

Figura 2. Mapeamento dos empreendimentos do PMCMV (faixa 1) no município de Paranavaí -PR

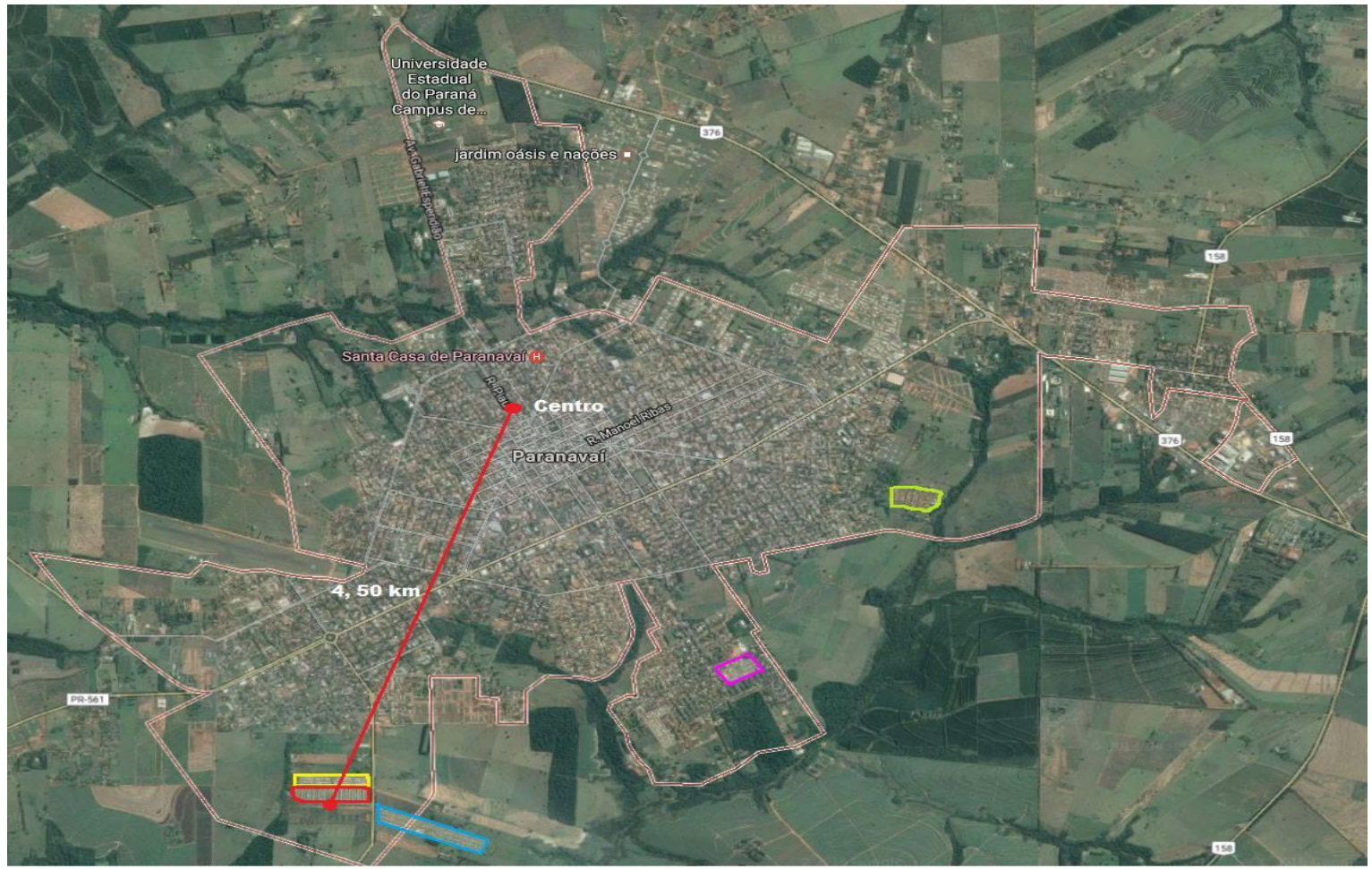

Conjunto Residencial Francisco Luis de Assis

Conjunto Residencial Vila Operária II Conjunto Residencial Luiz Lorenzetti Conjunto Residencial Flávio Ettore Giovine

Conjunto Residencial Geraldo Felippe

Fonte: Google Mapas, 2016. (Dados organizados pelos autores).

Conforme visualizado na figura 2, a distância total entre o Conjunto Residencial Geraldo Felippe e o centro da cidade é de 4,50 km. Assim, o indivíduo precisa atravessar a cidade, percorrendo $5,2 \mathrm{~km}$ a pé, o que corresponde à $1 \mathrm{~h} 8 \mathrm{~min}$, conforme dados contidos no Google Mapas (2017). Utilizou-se a alternativa "a pé", visto que a maioria das pessoas do conjunto não possui veículo próprio.

Assim, devido aos empreendimentos estarem localizados em áreas afastadas da cidade, há um impacto no cotidiano dos moradores em virtude de sua dinâmica com o novo espaço que, por sua vez, é atendido precariamente por serviços públicos e necessidades básicas.

\section{PROCESSO DE DES-RE-TERRITORIALIZAÇÃO DOS MORADORES DO CONJUNTO RESIDENCIAL GERALDO FELIPPE}

No decorrer de sua vida o indivíduo cria laços sociais e carrega consigo 
agentes sociais produtores do espaço urbano abrangem desde os proprietários dos meios de produção até os grupos sociais excluídos.

Assim, quando questionados sobre os lugares que moravam anteriormente, observa-se que a maioria dos entrevistados morava de aluguel ou na casa de algum parente. Embora diante de tais condições, os indivíduos relataram que tudo no espaço em que habitavam proporcionava maior acessibilidade a eles, visto que "tudo era mais perto".

Era tudo perto, padaria, mercado, tudo, tudo pertinho, nem ônibus precisava direito, porque era tudo muito perto. $\mathrm{O}$ acesso era fácil [...] (MARIA).

Eu morava lá no Ouro Branco [bairro de Paranavaí] de aluguel. [...] [Aqui é bom] só de não ter aluguel... Pra se deslocar pro serviço é ruim, né? [...] Quando eu tava pra lá, ia trabalhar de a pé, não precisava tá gastando. Tudo era mais perto, pra trabalhar você ia de a pé, voltava de a pé, que era perto (JOÃO).

Nos trechos que se seguem constata-se a (re)territorialização dos moradores por meio de palavras como "adaptar", "mexeu", "foi complicado no começo", uma vez que após o rompimento com o local anterior, tornaram-se necessárias novas formas de adaptação com o novo território. Mas, como foi salientado anteriormente, foi uma nova forma deles se organizarem, uma forma de (re)construção dos territórios (Haesbaert, 2006).

A gente teve que se adaptar. Foi difícil no começo, meu Deus! Por causa das crianças, automaticamente aumentou o combustível, porque isso mexeu com a renda da família. Mexeu com a gente. Embora a gente pague pouco, simbólico, a casa, mas mexeu no bolso. Mas, fora isso, a gente se adapta. Adaptei pra trabalhar. Pra mim, normal, só foi a questão do combustível... A gente viu que quase triplicou no mês. [...] [E] às vezes, meu filho mais velho que estuda do outro lado da cidade, pega dois ônibus pra ir pra escola. A minha filha mais nova, dos gêmeos, vai com meu esposo [de carro] [...] e eu vou de circular de manhã pro serviço e volto de circular do serviço (FRANCISCA).

Nós morava em casa de aluguel. Minha casa era grande, três quartos, sala, cozinha, quintal enorme. Quando nóis mudou pra cá... aqui é quarenta e dois metros... Pra você dar conta de por os móveis que você colocava numa casa de quase noventa metros, foi difícil. A única coisa que foi difícil pra se adaptar, não cabia nada, teve que desfazer das coisas. Os quartos das crianças tive que vender. Comprar beliche, porque tinha três filhos e não tinha quarto pra todo mundo. Aí comprei a beliche e uma cama de solteiro. Tivemos que desfazer de sofá, mesa não tenho aqui, porque é pequenininho. Mas, do mais, a casinha é boa. E depois que nóis murou tudo, fizemos a edícula, aí ficou melhor [...] Foi complicado no começo (ANA).

Conforme pode ser observado, verifica-se que devido às intervenções urbanas as pessoas têm suas práticas cotidianas modificadas. Além disso, houve uma desterritorialização atrelada a uma reterritorialização, visto que agora eles se veem num novo espaço e procuram novas formas de se organizar. Nota-se, ainda, que os sujeitos estão sob a lógica capitalista, evidenciando que foi uma segregação imposta, pois não tiveram alternativas de habitação. 
Como também, o que chama a atenção nos fragmentos acima é a forma com que a segregação está implicitamente apresentada. A distância afetou negativamente a vida destes indivíduos, haja vista que mexeu com a renda da família e com a forma com que eles se deslocam, seja para o trabalho, a escola, dentre outros lugares. Por esta razão, os moradores vão criando novas territorialidades em virtude das adversidades encontradas no território.

Percebe-se que os moradores apontam os benefícios recebidos. No caso dos trechos abaixo, será que eles querem transmitir um tipo ideal que condiz com o discurso dominante? Ou estão insistindo em desconstruir a imagem estigmatizada que o Conjunto transmite? Será que o intuito dessas mudanças estéticas era trazer benefícios para os moradores?

Eu gosto de andar. É gostoso ver como vai mudando assim. Você já entrou assim e via tudo, tipo, sem cerca, sem nada. E você vai vendo o progresso. Vai vindo, vai melhorando as coisas. É tão gostoso. Eu também gosto de caminhar, de andar de bicicleta. Aí você vai vendo assim, vai vendo que as coisas vai melhorando assim. Eu acho bem legal [...] Muro, cerca, portão assim, as pessoas aumentando as casas... A gente que faz isso, eles só entregam as casas, o muro, portão, a gente que se vira. Conversando com os vizinhos, um ajuda o outro e assim vai. E, no mais, eles terminando estas obras, tá terminando o posto, fazendo uma horta ali embaixo, na praça [...] E é isso, mudança assim e as pessoas aumentaram as casas (MARIA).

Bom, eles já fizeram uma escola ali em cima. Então, já passei minha filha pra cá, que já é uma coisa boa. Tá saindo a UBS [Unidade Básica de Saúde] aqui embaixo. Já tem uma horta comunitária que tá saindo aqui embaixo também [...] Então, tudo isso aí já ajuda bastante. A única coisa que eu sinto falta aqui perto é uma farmácia. Mas, no restante eles estão providenciando tudo. Quando as crianças ficam doentes, a sorte é que eu tenho o carro ainda (FRANCISCA).

Os agentes produtores do espaço urbano com poder dominante vão buscar melhores áreas, mas os grupos sociais excluídos não terão alternativas de moradia, a não ser lugares periféricos da cidade. Por esta razão, como fica explícito no depoimento abaixo, embora tenha a "casa própria", o problema da acessibilidade clama por socorro nas falas dos entrevistados.

[...] Quando a gente mudou pra cá foi bom, porque por um lado e por outro... porque tudo na vida tem dois lados, não tem jeito. Lá [lugar em que morava antes] eu tava morando de favor na casa da minha mãe, porque eu não tinha condição de pagar aluguel. Aqui, pelo menos, a casa é minha, casa própria, a gente tá pagando uma coisa que é nossa, eu pago bem pouquinho, que já ajuda bastante. Mas, em tempo de crise ainda tá meio difícil. E é isso. A única coisa que a gente pode falar um pouquinho, reclamar um pouquinho, é esse negócio de acessibilidade (MARIA).

Chama a atenção, ainda, o modo como os moradores se referem ao
anciamento. Nos próximos depoimentos, por exemplo, verifica-se que eles usam os termos "Ionjura" e "arrabalde" no intuito de exporem a distância percebida em relação à cidade. 
O que menos me atrai é a lonjura. Meu pai e minha mãe mora lá no Guanabara. E pra lá, você quer uma farmácia, você tem perto. Posto de saúde é perto. Você quer ir no mercado, é perto. Aqui tudo que você tem que fazer, você faz fora, porque se for comprar aqui dentro... [...] Então, qualquer saidinha que você sai, pra colocar no veículo aí, você não vai de a pé. Que nem eu que só tenho carro, qualquer "idinha" lá no centro e voltar aqui, é vinte conto de combustível que vai [...] Quando eu trabalhava [...] eu tinha que sair daqui e ir lá no barracão, lá no Sumaré. Tinha que atravessar a cidade inteirinha. Se não for o carro pra ir lá, como que você vai? [...] Nossa! Aqui eles tinham que abrir rua, sei lá, pra cá, fazer qualquer coisa pra se tornar mais perto (JOÃO).

Tudo é longe, é arrabalde da cidade, né? [...] Tipo assim: mercado, o melhorzinho mais barateiro aqui, um pouquinho maior é o "Coapar". Entendeu? Que acompanha o preço dos outros mercados. E no mais, os outros mercadinhos aqui são bem "carinho", "enfiam a faca" [...] E no mais é tudo longe [...] [E] quando eu tenho dinheiro pra circular, pra condução, eu vou de circular. Quando é um vizinho ou um parente que ajuda com carona, vai de carona [...] Mas, no mais é a pé. Quando não tem, é a pé. É aquilo que eu te falei, quando tem condução, tem. Quando não tem, tem que ser do jeito que dá, moça. Sol escaldante. É difícil. Não é fácil, não! (MARIA).

Se eu tenho que fazer alguma coisa pra fora, banco, alguma coisa, vou pro centro, aí ou você tira o dia pra fazer tudo, ou senão você só gasta, porque vai e vem, é longe, né? Aí eu tiro um dia, vou, faço tudo. Tem dia que eu fico até duas ou três horas da tarde na rua, pra resolver tudo (ANA).

Ficou notável durante a realização das entrevistas que o poder público realizou a obra, mas não teve uma visão dos aspectos necessários para o dia a dia dos moradores, ou seja, uma visão integradora, negligenciando, desta forma, o aspecto territorial.

De forma geral, para os moradores desenvolverem suas atividades essenciais, eles precisam deslocar-se ao centro da cidade, despendendo horas para ter acesso ao trabalho, escola, posto de saúde, farmácia, e consumindo mais tempo e dinheiro para acessar os serviços básicos.

Além do exposto, a dificuldade de acesso à área central da cidade se materializa no cotidiano dos moradores, pois devido à rodovia ser o único meio de acesso à cidade como asseverado por eles, houve uma restrição/limitação na vida dos moradores, conforme relatos a seguir.

Eles precisam fazer calçada e ciclovia aqui pra gente. O povo aqui do Lorenzetti [o outro Conjunto Habitacional], eles têm que passar no meio da rodovia, pra ir pro conjunto deles. E nóis aqui, a gente tem que atravessar areião com carrinho, com cadeira de rodas, eu já vi cadeirante assim, empurrando em meio à areião. Pensa que dificuldade! Quando chove, isso é pior. Bicicleta, se você não quiser passar no areião, você vai ter que disputar espaço na rodovia. É um absurdo isso! Já que aumentou a cidade pra cá, então dá condição! Vai ter que colocar um semáforo, mais iluminação, mais calçada, ciclovia. Tem que dá condição pro povo andar. Porque quem tem, tem e que não tem, fica na dificuldade, 
sofre, moça sofre muito. Ele não pode ser tão egoísta assim. Tipo: deu as casinhas e já se dê por satisfeito. Não é bem assim, entendeu? A gente também paga imposto e quer ver o retorno, poxa! Não é bem assim! (MARIA).

[...] Eu acho que deveriam ter pensado nisso antes de entregar os três conjuntos, porque é praticamente uma cidade se você for ver. É muita casa, é muita gente (FRANCISCA).

Quando questionados sobre o que mais gostam, os moradores afirmaram gostar do lugar, dando uma importância material e simbólica. Vê-se isso, porque a casa foi a realização da família. Além disso, ela representa o lugar de satisfação dos moradores, em que eles produziram significados. Entretanto, por mais que haja este "gostar", os moradores insistiram em reafirmar que sejam postas melhorias no local.

Bom, eu gosto daqui, gostei daqui desde sempre, assim. Mas, é isso... é só trazer mais condição pra cá e conforme o tempo for passando também. Tudo é natural. Isso aqui menina, vai ficar uma beleza. Uma maravilha (MARIA).

No trecho abaixo percebe-se que o morador sente-se completamente desterritorializado do local que vivia antes.

Aqui me sinto um pouco perturbado, porque é muito barulho. Onde que eu morava não tinha barulho. De vizinho com som alto demais. Quando eu morava lá, pros lado de lá, era muito pouco. Aqui é vizinho brigando um com o outro (JOÃO).

Mas, ainda há a questão da segregação socioespacial que se mostra diariamente na vida dos moradores contemplados pelo PMCMV, apresentando-se por meio da ausência de alguns serviços públicos essenciais, conforme as críticas abaixo.

[...] a única coisa que tá dificultando é Correios, porque não passa. Então, dificulta bastante, né? A gente tem que ir sempre pro centro, buscar documento, os papel, né? Quanto ao posto, o duro é que a gente tem que ir para o Campo Belo. Mas, falaram que agora em Janeiro vai inaugurar já o posto, né? Vamos ver, né? (APARECIDA).

O que eu mais gosto é das vizinhas, gosto da casa - casinha boa, quintal grande. E o que eu menos gosto, é que deveria ter rede de esgoto. E não tem rede de esgoto, tem fossa. Daí fica com mal cheiro. Quer ver quando vai chover mesmo, fica fedendo o banheiro, fede a caixinha da pia [...] (ANA).

Embora a quantidade de moradias entregues as famílias de baixa renda seja considerada, o programa tem sofrido críticas, voltadas principalmente a localização dos empreendimentos e a falta de infraestrutura adequada. Nesse contexto, enfatiza-se que os moradores do Conjunto são obrigados a percorrer longas distâncias, visto que não foi instalado no conjunto este tipo de infraestrutura para atender às suas necessidades.

Deste modo, nos trechos abaixo verifica-se que não há oferecimento de projetos de esporte, cultura e lazer para os moradores, o que reforça ainda mais a segregação e a desterritorialização, pois a distância e a ausência de atividades para eles faz com que se sintam ainda mais excluídos. 
Bom, eu não saio de casa. Praticamente só dentro de casa [...] Não saio, quando saio, eu pego o carro e vou pro centro, para os outros lugares. Eu não fico aqui, porque aqui não tem nada pra fazer, não tem um lazer para as crianças. Não tem nada. Então, eu dou uma saída (FRANCISCA).

Não costumo sair ou andar pelo bairro. Somente fico em casa. Mas no meu ponto de vista, não tem nada para se fazer aqui, pois, não há áreas de lazer, como praças (SELMA).

Diante desta situação, os moradores do Conjunto Residencial Geraldo Felippe foram antes desterritorializados em função do deslocamento de sua antiga moradia. Bem como, o processo de reterritorialização foi ocorrendo na medida em que eles começaram a organizar novas formas de apropriação do espaço. Assim, esta situação corrobora os argumentos de Raffestin (1984), onde o indivíduo está criando, destruindo e criando territórios constantemente.

Entretanto, observa-se certa ligação com o local de moradia anterior, além da opção por bairros que sejam mais próximos ao centro e que atendam às suas necessidades.

[...] A gente prefere num bairro assim mais perto, assim, de progresso, de tudo [...] Já pensei em Ipê, Vila City, que eu acho que são bairros bem gostosos, bem familiar, que já tá mais perto das coisas, de centro, assim mais ou menos (MARIA).

Eu morava lá no Morumbi, eu voltaria pra lá, porque é um bairro sossegado. As minhas irmã mora lá. Meu pai mora lá na Vila Rural que é próximo lá [Morumbi]. Eu preferia lá (CLEUZA).

Eu voltava pra onde eu morava, porque lá é mais sossegado, mais tranquilo, não tem tanta molecada [...] Se fosse pra mudar, tipo, se pudesse trocar a casa, o lugar da casa, era pra lá, no Jardim Guanabara (JOÃO).

Assim, constata-se que houve o processo T-D-R com os moradores contemplados pelo PMCMV (faixa 1), ficando visível o consequente processo de segregação socioespacial, em virtude da ação dos agentes sociais.

\section{CONSIDERAÇÕES FINAIS}

A cidade está inserida no espaço urbano, sendo permeada por relações sociais e espaciais. Assim, considerando-a como uma megaorganização, é preciso saber geri-la, posto que "o uso da cidade como objeto de análise abre possibilidades interessantes de se contribuir para o estudo de organizações complexas" (Fischer, 1996, p. 14), ou seja, ao compreendê-la como organização, torna-se possível utilizar recursos para sua melhor gestão.

Entretanto, ao tratar a cidade como mercadoria, o Estado que se apodera de amplos instrumentos regulamentários, realiza intervenções urbanas que afetam negativamente a vida de pessoas de forma direta e/ou indireta. Porém, com o intuito de enriquecer o campo dos Estudos Organizacionais, é preciso considerar não apenas estudos funcionalistas, mas adentrar o cotidiano dos moradores que, no caso do PMCMV, sofrem o processo T-D-R.

Diante desta situação, tendo por objetivo compreender como ocorreu o processo de (re)territorialização dos moradores do Conjunto Residencial Geraldo 
Felippe no município de Paranavaí - PR, a partir da intervenção do Programa Minha Casa Minha Vida (faixa 1), por meio das entrevistas com os moradores, pôde-se compreender como está sendo o processo de (re)territorialização após a mudança ao conjunto. As entrevistas mostraram, ainda, que a região periférica restringe os moradores do acesso a serviços básicos, causando, desta forma, uma segregação socioespacial.

Com este estudo, percebe-se que ao realizar moradias destinadas às famílias de rendas menores, o poder público desconsidera determinados aspectos, o que impacta negativamente a vida dos moradores. Pois, no processo de territorialização-desterritorialização-reterritorialização, os indivíduos afirmaram que gostariam de voltar a morar no local anterior, pois possuem laços simbólicos, além de apontarem que a distância é um fator que afeta as suas vidas, principalmente, no modo como eles têm que se organizar em seu novo território.

Diante desta perspectiva, a pesquisa proporciona um avanço ao campo dos Estudos Organizacionais, demonstrando como as intervenções urbanas afetam a vida de moradores contemplados pelo PMCMV. E, desta forma, busca-se provocar uma reflexão sobre o movimento T-D-R relacionado à produção habitacional atual brasileira.

Ademais, as contribuições proporcionadas por este estudo mostram que na formulação de uma política habitacional é necessário ter uma visão integradora, não negligenciando os aspectos territoriais, uma vez que tais intervenções impactam a organização territorial da cidade e consequentemente o cotidiano dos indivíduos. Além disso, espera-se que este estudo amplie o conhecimento sobre o processo T-D-R em relação às implicações das intervenções urbanas na organização territorial da cidade e na vida da população citadina.

Por fim, esta pesquisa focou no estudo do Conjunto Residencial Geraldo Felippe, mas limitou-se a estudar os demais conjuntos habitacionais da faixa 1 do município. Assim, sugere-se outras pesquisas, tendo em vista que todos estão em localizações periféricas da cidade, dificultando o acesso ao centro, aos serviços públicos e às demais necessidades básicas. Por esta razão, apontam-se como perspectivas para estudos futuros sobre território, a possibilidade de serem investigados os processos T-D-R nos demais conjuntos habitacionais de Paranavaí, assim como a compreensão dos conflitos de interesses entre o capital e o social no que tange às políticas habitacionais, compreendendo, desta forma, como as intervenções urbanas afetam o espaço da cidade. 


\title{
The process of des-re-territorialization of the residents of the geraldo felippe housing complex in the city of paranavaí-pr: an urban intervention from the Minha Casa Minha Vida program
}

\begin{abstract}
Although the urban space is produced by various social agents, the State exerts a relevant role in your production. However, in certain situations he resorts to economic factors, without considering political, cultural and, mainly, social aspects. With housing policies, individuals are get around to distant places downtown, to going down a process of territorialization-deterritorialization-reterritorialization (T-D-R). Based on this perspective, this paper aims to understand how occurred the process of (re) territorialization of the residents of the Geraldo Felippe Housing Complex in the city of Paranavaí - PR, from the intervention of the Minha Casa Minha Vida Program - PMCMV (track 1). Thus, a qualitative and descriptive study was conducted, involving semi-structured interviews with the residents. For the interpretation of the data collected, it was used technique of the content analysis. It has been found that residents explicitly have a sense of happiness for "homeownership" however, implicitly, there are differences in relation to the territory they lived before and what they now live. Main results suggest that in the formulation of a housing policy should to have an integrative vision, not neglecting the territorial aspects, since such interventions impact the territorial organization of the city and, consequently, the daily of individuals.
\end{abstract}

KEY WORDS: Urban space. Territory. Process of territorialization-deterritorializationreterritorialization. Minha Casa Minha Vida Program. Housing Complex Geraldo Felippe. 
ALMEIDA, M. S.; MELCHIORS, L. C. A produção do espaço urbano e da habitação social na escala metropolitana: efeitos do programa Minha Casa, Minha Vida na região metropolitana de Porto Alegre/RS. REDES - Revista do Desenvolvimento Regional, v. 22, n. 1, p.142-161, 2017.

BALBIM, R.; KRAUSE, C.; NETO, V. C. L. Para além do Minha Casa Minha Vida: uma política de habitação de interesse social? Rio de Janeiro: Ipea, 2015.

BARDIN, L. Análise de conteúdo. Lisboa: Edições 70, 1977.

BOTELHO, A. O urbano em fragmentos: a produção do espaço e da moradia pelas práticas do setor imobiliário. São Paulo: Annablume; Fapespe, 2007.

BRASIL. Programa Minha Casa Minha Vida. Ministério das Cidades. 2016. Disponível em: <http://www.minhacasaminhavida.gov.br>. Acesso em 29 dez. 2016.

CADONÁ, M. A.; TIRELLI, C.; AREOSA, S. V. C. Políticas habitacionais, segregação residencial e desigualdade no acesso às políticas públicas: uma análise a partir do acesso a serviços públicos de saúde. REDES - Revista do Desenvolvimento Regional, v. 22, n. 1, p. 326-345, 2017.

CANDIOTTO, L. Z. P.; SANTOS, R. A. Experiências geográficas em torno de uma abordagem territorial. In: SAQUET, M. A.; SPOSITO, E. S. (Org.). Territórios e territorialidades: teorias, processos e conflitos. São Paulo: Expressão Popular, 2009.

Cardoso, A. L.; Mello, I. Q.; Jaenisch, S. T. A implementação do Programa Minha Casa Minha Vida na Região Metropolitana do Rio de Janeiro: agentes, processos e contradições. In: Amore, C. S.; Shimbo L. Z.; Rufino, M. B. C. Minha Casa... E a Cidade? Avaliação do Programa Minha Casa Minha Vida em seis estados brasileiros. 1 ed. Rio de Janeiro: Letra Capital, 2015.

CARLOS, A. F. A. O Espaço Urbano: Novos Escritos sobre a Cidade. São Paulo: FFLCH, 2007.

CARVALHO, C.; PATRÍCIO, N.; SCHUETT, N. A importância das áreas de uso comum em projetos de habitação social: o caso do Programa Minha Casa Minha Vida. Revista Brasileira de Planejamento e Desenvolvimento, v. 3, n. 2, p. 24-35, 2014. 
COELHO, K. S. A Resistência à nova proposta de Plano Diretor apresentada pela Prefeitura Municipal de Florianópolis: uma análise das práticas alternativas de organizar. Tese de Doutorado (Programa de Pós-Graduação em Administração) Universidade Federal de Santa Catarina, Florianópolis, 2012.

CORRÊA, R. L. Espaço, um conceito chave da geografia. In: CASTRO, I. E.; GOMES, P. C. C.; CORRÊA, R. L. Geografia: conceitos e temas. 2 ed. Rio de Janeiro: Bertrand Brasil, 2000.

O espaço urbano. São Paulo: Ática, 2004.

Sobre agentes sociais, escala e produção do espaço: um texto para discussão In: CARLOS, A. F. A.; SOUZA, M. L.; SPOSITO, M. E. B. (Orgs.). A produção do espaço urbano: agentes e processos, escalas e desafios. São Paulo: Contexto, 2013.

DAVEL, E.; ALCADIPANI, R. Estudos críticos em administração: reflexões e constatações sobre produção brasileira. In: Encontro de Estudos Organizacionais, 2, 2002, Recife. In: Anais do... Observatório da Realidade Organizacional: PROPAD/UFPE: ANPAD, 2002.

FERREIRA, R. F. Movimentos sociais, autogestão e a construção da política nacional de habitação no Brasil. In: LAGO, L. C. Autogestão habitacional no Brasil: utopias e contradições. Rio de Janeiro: Letra Capital/Observatório das Metrópoles, 2012.

FISCHER, T. A cidade como teia organizacional: inovações, continuidades e ressonâncias culturais Salvador, BA, cidade puzzle. Revista de Administração Pública, v. 31, n. 3, p. 74-88, 1997.

FISCHER, T. Gestão contemporânea, cidades estratégicas: aprendendo com fragmentos e reconfigurações do local. In: FISCHER, T. (Org.). Gestão contemporânea: cidades estratégicas e organizações locais. Rio de Janeiro: Editora da FGV, 1996.

HAESBAERT, R. Des-caminhos e perspectivas do território. In: RIBAS, A. D.; SPOSITO, E. S.; SAQUET, M. A. Território e desenvolvimento: diferentes abordagens. Francisco Beltrão: Unioeste, 2004.

Da desterritorialização à multiterritorialidade. Anais do X Encontro de 2005. 
. Territórios Alternativos. 2 ed. São Paulo: Contexto, 2006.

Concepções de território para entender a desterritorialização. In: SANTOS, M.; BECKER, B. K. (Org.). Território, Territórios: ensaios sobre o ordenamento territorial. 3 ed. Rio de Janeiro: Lamparina, 2007.

HAESBAERT, R.; BRUCE, G.. A Desterritorialização na Obra de Deleuze e Guattari. GEOgraphia, v. 4, n. 7, p. 3-11, 2002.

IBGE - INSTITUTO BRASILEIRO DE GEOGRAFIA E ESTATÍSTICA (2016). Cidades. Disponível em: <http://www.cidades.ibge.gov.br>. Acesso em: 27 dez. 2016.

KLINTOWITZ, D. C.; RUFINO, M. B. C. A produção do Programa Minha Casa, Minha Vida na Região Metropolitana da Baixada Santista: reafirmação da configuração metropolitana e exclusão socioterritorial. Revista Pensamento \& Realidade, v. 29, n. 3, p. 116-134, 2014.

LAGO, L. C. Autogestão habitacional no Brasil: utopias e contradições. Rio de Janeiro: Letra Capital/Observatório das Metrópoles, 2012.

LEFEBVRE, H. La production de l'espace. 4 éd. Paris: Éditions Anthropos, 2000.

MARQUES, E.; RODRIGUES, L. O Programa Minha Casa Minha Vida na metrópole paulistana: atendimento habitacional e padrões de segregação. Revista Brasileira de Estudos Urbanos e Regionais, v. 15, n. 2, p. 159-177, 2013.

MELCHIORS, L. C. A habitação social brasileira recente: entre sonho, necessidade, marketing e remoções. In: 10 Colóquio Internacional de História Cultural da Cidade: Sandra Jatahy Pesavento, 2015.

MELCHIORS, L. C.; ALMEIDA, M. S. Entre o sonho e a realidade: a habitação social no Brasil de uma perspectiva histórica. Arquisur Revista, v. 7, n. 5, p. 46-59, 2015.

MINAYO, M. C. S. (Org). Pesquisa Social: teoria método e criatividade. Petrópolis, RJ: Vozes, 1994

MINEIRO, E. H.; RODRIGUES, E. Do crédito solidário ao MCMV entidades: uma história em construção. In: LAGO, L. C. Autogestão habitacional no Brasil: utopias e contradições. Rio de Janeiro: Letra Capital/ Observatório das Metrópoles, 2012. 
MISOCZKY, M. C.; AMANTINO-DE-ANDRADE, J. Uma crítica à crítica domesticada nos estudos organizacionais. Revista de Administração Contemporânea, v. 9, n. 1, p. 192-210, 2005.

MOURA, J. M. O Programa Minha Casa, Minha Vida na Região Metropolitana de Natal: uma análise espacial dos padrões de segregação e desterritorialização. URBE. Revista Brasileira de Gestão Urbana, v. 6, n. 3, p. 339-359, 2014.

NASCIMENTO, D. M.; Costa, H. S. M.; Mendonça, J. G.; Lopes, M. S. B.; Lamounier, R. F.; Salomão, T.; Soares, A. C. B. Programa Minha Casa Minha Vida: desafios e avanços na Região Metropolitana de Belo Horizonte. In: AMORE, C. S.; SHIMBO, L. Z.; RUFINO, M. B. C. Minha Casa... E a Cidade? Avaliação do Programa Minha Casa Minha Vida em seis estados brasileiros. 1 ed. Rio de Janeiro: Letra Capital, 2015.

PREFEITURA MUNICIPAL DE PARANAVAÍ. Conjuntos habitacionais Geraldo Felippe e Francisco Luiz de Assis serão inaugurados nesta sexta-feira. 2015. Disponível em: <http://www.paranavai.pr.gov.br/>. Acesso em: 15 dez. 2016.

RAFFESTIN, C. Por uma geografia do poder. São Paulo: Ática: 1993.

ROLNIK, R., PEREIRA, A.; MOREIRA, F.; ROYER, L.; lacovini, R.; Nisida, V. C.; Lopes, A. P. O.; Rossi, L. O Programa Minha Casa Minha Vida nas Regiões Metropolitanas de São Paulo e Campinas: aspectos sócio-espaciais e segregação. Caderno Metrópoles, v. 17, n. 33, p 127-154, 2015.

SACK, R. D. Human territoriality: its theory and history. Cambridge: Cambridge University Presse, 1986.

SAQUET, M. A. Abordagens e concepções de território. Expressão Popular: São Paulo, 2007.

SAQUET, M. A. Construindo uma proposta de abordagem territorial (i)material. In: SAQUET, M. A. (Org.). Abordagens e concepções de território. 3 ed. São Paulo: Outras Expressões, 2013.

SAQUET, M. A. Por uma abordagem territorial. In: SAQUET, M. A.; SPOSITO, E. S. Territórios e territorialidades: teorias, processos e conflitos. Expressão Popular: São Paulo, 2009.

SARAIVA, L. A. S.; CARRIERI, A. P. Organização-cidade: proposta de avanço 
SILVA, P. M. S. História de Paranavaí. 2 ed. Paranavaí, Fundo Municipal de Cultura, 2014.

SILVA, M. L; TOURINHO, H. L. Z. O Banco Nacional de Habitação e o Programa Minha Casa Minha Vida: duas políticas habitacionais e uma mesma lógica locacional. Cadernos Metrópole, v. 17, n. 34, p. 401-417, 2015.

SOUZA, M. L. "Território" da divergência (e da confusão): em torno das imprecisas fronteiras de um conceito fundamental. In: SAQUET, M. A.; SPOSITO, E. S. (Org.). Territórios e territorialidades: teorias, processos e conflitos. São Paulo: Expressão Popular, 2009.

O território: sobre espaço e poder, autonomia e desenvolvimento. In: CASTRO, I. E.; GOMES, P. C. C.; CORRÊA, R. L. Geografia: conceitos e temas. 15 ed. Rio de Janeiro: Bertrand Brasil, 2012.

TRIVIÑOS, A. N. S. Introdução à pesquisa em ciências sociais: a pesquisa qualitativa em educação. São Paulo: Atlas, 1987.

VIEIRA, M. M. F.; ZOUAIN, D. Pesquisa qualitativa em administração: teoria e prática. Rio de Janeiro: Editora FGV, 2005.

Recebido: 25 out. 2019.

Aprovado: 24 nov. 2019

DOI: $10.3895 /$ rbpd.v9n2.8988

Como citar: SILVA, D. A. S.; CHAGAS, P. B. O processo de des-re-territorialização dos moradores do conjunto residencial geraldo felippe no município de paranavaí-pr: uma intervenção urbana a partir do programa Minha Casa Minha Vida. R. bras. Planej. Desenv. Curitiba, v. 9, n. 2, p. 147-170, mai./ago. 2020

Disponível em: <https://periodicos.utfpr.edu.br/rbpd>. Acesso em: XXX.

Correspondência:

Dayane Alves de Souza Silva

Av. Colombo, 5790 - Zona 7 - Maringá, PR

Direito autoral: Este artigo está licenciado sob os termos da Licença CreativeCommons-Atribuição 4.0

Internacional. 